\title{
Selectionism and Diaphaneity
}

\author{
Paweł Jakub Zięba ${ }^{1}$
}

Received: 12 September 2021 / Accepted: 24 November 2021 / Published online: 2 December 2021

(c) The Author(s) 2021

\begin{abstract}
Brain activity determines which relations between objects in the environment are perceived as differences and similarities in colour, smell, sound, etc. According to selectionism, brain activity does not create those relations; it only selects which of them are perceptually available to the subject on a given occasion. In effect, selectionism entails that perceptual experience is diaphanous, i.e. that sameness and difference in the phenomenal character of experience is exhausted by sameness and difference in the perceived items. It has been argued that diaphaneity is undermined by phenomenological considerations and empirical evidence. This paper considers five prominent arguments of this sort and shows that none of them succeeds.
\end{abstract}

Keywords Selectionism · Diaphaneity · Relationalism · Perception · Consciousness

\section{Introduction}

The perceived differences and similarities in sensory qualities such as colour or smell are determined by neural activity in our brains. According to the idea known as 'selectionism', brain activity does not create those relations; it just selects which of them are perceptually available to the subject on a given occasion. A straightforward consequence of selectionism is the diaphaneity thesis ${ }^{1}$, according to which sameness and difference in the phenomenal character of perceptual experience is exhausted by sameness and difference in the perceived items. Many philosophers believe that this consequence renders selectionism unacceptable. Some of them argue that diaphaneity is undermined by phenomenological considerations, others find it incompatible with empirical evidence.

\footnotetext{
${ }^{1}$ This is not to say that all formulations of selectionism entail that experience is fully diaphanous. Different versions of selectionism vary in scope, and the scope of diaphaneity depends on the scope of selectionism. I say more about this in Sects. 2 and 3.
}

Paweł Jakub Zięba

pj.zieba@uj.edu.pl

1 Jagiellonian University, Kraków, Poland 
This paper considers five prominent objections of this sort and shows that none of them reaches the target. More specifically, I argue that phenomenological observations and empirical findings on which these objections are based can be plausibly explained in terms of selectionism and diaphaneity. While both claims could still be contested on some other grounds, the availability of such alternative explanations shows that they are not nearly as easy to refute as they are often taken to be.

To be clear, my aim is not to show that in each case an explanation in terms of selectionism and diaphaneity is the only way to go. To make my point, I only need to show that such an explanation is available and has some substantial motivation.

My defence of diaphaneity rests on three fundamental assumptions: (i) there is a clear distinction between perception and cognition; (ii) a single object can have both physical and non-physical properties; (iii) the phenomenal character of perceptual experience does not depend on consciousness for its existence. While the opponent of diaphaneity might find these claims exceptionable, they cannot be dismissed without argument. Unless they are proven false, diaphaneity is immune to the objections discussed in this paper, and selectionism remains a viable option.

Section 2 spells out selectionism using colour perception as an example. Section 3 introduces diaphaneity as a corollary of selectionism. Sections 4 and 5 defend diaphaneity from phenomenological objections concerning the boundaries of visual experience and blurry vision. Sections 6, 7 and 8 defend diaphaneity from empirical objections concerning attentional variation, the correlation between perceptual phenomenal character and various physical properties, and unconscious perception. Section 9 argues that selectionism is preferable over non-selectionist attempts to preserve the objectivity of perceptual phenomenal character. Section 10 concludes.

\section{Selectionism}

In everyday life, we tend to treat colours as objective because colour perception affords us knowledge about the environment. Perceiving changes in colour informs us that it is safe to cross the street, that the food is cooked, and so on. However, colour objectivism is challenged by colour variation (see e.g. Burnyeat 1979; Block 1999; Mizrahi 2006; Kalderon 2007; Allen 2016). There are three kinds of such variation: (i) intersubjective (the same object in the same conditions can appear to have some colour to one subject and a different colour to another subject); (ii) intrasubjective (the same object can appear to have different colours to the same subject in different conditions); (iii) inter-species (the same object in the same conditions can appear to have different colours to members of different species). The apparent clash between the pre-theoretical colour objectivism and colour variation leads to the following paradox (Kalderon 2007, 567):

(A) $\mathrm{x}$ appears $\mathrm{F}$ and $\mathrm{x}$ appears $\mathrm{G}$.

(B) The F-appearance and the G-appearance are both veridical.

(C) Nothing is both F and G. 
While each of these claims seems plausible when considered separately from the remaining two, together they are inconsistent. Something has got to give.

One possible resolution to the paradox is selectionism, which consists in accepting $\mathrm{A}-\mathrm{B}$ and rejecting $\mathrm{C}$. The rejection of $\mathrm{C}$ entails colour pluralism, i.e. the idea that a single object has multiple colours all over at the same time. This allows the selectionist to argue that colour variation occurs because different colours of a single object are perceptually available in different conditions, and to different subjects. Whenever two subjects perceive different colours while seeing the same object in the same circumstances, this is because their respective visual systems select (e.g. render visually available) different colours of that object (Kalderon 2007, 593; cf. Allen 2016, 66-73). In effect, selectionism accommodates colour variation while preserving colour objectivism.

Selectionism can be unpacked in different ways, and thereby admits of being incorporated into different theoretical frameworks. For instance, various forms of selectionism differ with respect to what is selected (i.e. what properties we perceive). When it comes to colour perception, it can be colours qua sensory qualities (Allen 2016; Mizrahi 2006), sensible aspects of colours (Kalderon 2008), shades determined by colours and illumination (Fish 2009), or objective appearances determined by intrinsic properties of objects and environmental conditions (Genone 2014). The issue of what is selected complicates when one tries to extend selectionism to properties other than colours, and to sense modalities other than vision. In what follows, I defend a version of selectionism according to which the perceptual system selects instances of proper sensibles and aspects of instances of common sensibles ${ }^{2}$.

Relatedly, various versions of selectionism differ in scope (see also Section 2). For example, Allen (Allen 2016, 66-67) claims that extending selectionism to all cases of intra- and inter-subjective variation is neither mandatory nor preferable, even after one applies it to inter-species variation. It is not mandatory because intersubjective variation is much smaller than sometimes suggested, and when it comes to perception of relatively coarse-grained colours (e.g. green, red, blue, yellow), experiences of normal perceivers converge sufficiently to justify the mind-independence of colours (Allen 2016, 61). It is not preferable in that it makes it hard to explain constancy in colour perception.

Yet there is an alternative. Mizrahi (2006), who endorses selectionism with respect to all kinds of perceptual variation, accounts for colour constancy by distinguishing two different concepts of colour: colour ${ }_{1}$ and colour ${ }_{2}$. Selectionism is primarily a claim about colours. Those are the colours we see. By contrast, an object can have only one colour ${ }_{2}$ at any given time. Colours ${ }_{2}$ are not experienced directly but through a change in colour ${ }_{1}$. If a change in illumination reveals a difference in

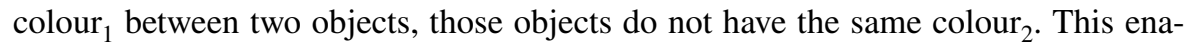
bles one to endorse selectionism about all kinds of colour variation while still being able to account for colour constancy. That each object has multiple colours ${ }_{1}$ does not

\footnotetext{
${ }^{2}$ Common sensibles (a.k.a. primary qualities) are qualities perceivable by more than one sense (e.g. size, shape, solidity, number, rest, motion). Proper sensibles (a.k.a. secondary qualities) are qualities perceivable by a single sense (e.g. colour, smell, taste, sound, warmth or cold, and so on).
} 
entail that each object has those colours in the same way. Mizrahi $(2006,296)$ illustrates this by comparing a ripe banana in red light to a ripe tomato in daylight. They have the same colour ${ }_{1}$ but differ with respect to colour ${ }_{2}$.

Regarding the metaphysics of colour, selectionism entails colour realism (the view that colours are real) and consorts with colour objectivism (the view that colours are environmental features that exist independently of being perceived $)^{3}$. Selectionism is also neutral regarding the reducibility of colours to physical properties. It is compatible with both colour reductionism, which identifies colours with reflectances over one or many wavelength intervals (Mizrahi 2006), and colour primitivism, which construes them as simple, sui generis properties, not identical to physical properties (Kalderon 2007, 2011b; Allen 2016).

Selectionism partially explains the nature of the phenomenal character of perceptual experience, which is a set of qualities that determine what it is like to have a perceptual experience (Coates and Coleman 2015, 2). Primitivist selectionism is often combined with the relational theory of perception, according to which the phenomenal character of perceptual experience is at least partially constituted by the mind-independent object (see e.g. Brewer 2011; Campbell 2002; Martin 2004). This leads to the view that the perceptual system can select different property instances the perceived object instantiates on different occasions.

That said, selectionism is not incompatible with relationalism's main rival, i.e. intentionalism about perception, which construes perception as a mental representation that represents the world as being a certain way (see e.g. Siegel 2010). On that view, the phenomenal character of perceptual experience is not constituted by the mind-independent object because it is consistent with inexistence of the perceived object. Intentionalist selectionism claims that the perceptual system selects which features of the environment are perceptually represented on a given occasion.

Nevertheless, below I defend only the primitivist-relationalist version of selectionism because (i) reductionist selectionism is undermined by empirical evidence (see Sect. 7), and (ii) my replies to phenomenological objections to selectionism partially rest on scepticism concerning the idea that perceptual experience has intentional content (see Sect. 5).

\section{Diaphaneity}

If the perceptual system merely selects which parts of the environment constitute perceptual phenomenal character, it does not add anything non-environmental to that character. It follows that the selected (and thereby perceived) items are the only constituents of perceptual phenomenal character. Unless qualified in some way (e.g. restricted in scope to a single sensible quality or a single sense modality), selectionism entails that:

\footnotetext{
3 A conjunction of selectionism and colour subjectivism is coherent but implausible (cf. Beck 2019a, 618).
} 
(Diaphaneity) Sameness and difference in phenomenal character between any two perceptual experiences is entirely constituted by sameness and difference in the perceived items (cf. Martin 1998, 175).

It is the commitment to diaphaneity that the critics of various forms of selectionism find incompatible with phenomenological observations and empirical evidence. Before I consider their arguments, I need to make some clarifications.

First, the scope of diaphaneity depends on the scope of selectionism. For example, if one endorses selectionism only with respect to inter-species variation in colour perception, one is only committed to diaphaneity as far as that variation is concerned. On this view, differences in colour experience between members of different species are explained by suggesting that they perceive different colours, whereas other differences in colour experience can be explained by suggesting that the same colour is perceived in two different ways (whatever that might mean). This shows that there are intermediate options between full diaphaneity and unreserved denial of diaphaneity.

Although selectionism is typically endorsed in a restricted form (i.e. applied locally to a certain type of phenomenal difference), there are at least two theories of perception that are arguably committed to unrestricted selectionism (and thereby also to full diaphaneity). The first is Travis' relationalism (Travis 2004), according to which the senses merely bring things in view for the subject, without specifying how things are. The second is Pure Relationalism identified (but not endorsed) by Stoneham (2008), according to which perception occurs in the environment, not in the subject. In this connection, the reasons to endorse selectionism and diaphaneity ensue from (or simply overlap with) the motivations behind the forms of relationalism that are committed to selectionism and diaphaneity ${ }^{4}$.

This paper is neutral about the question of whether totally unrestricted selectionism is tenable. Its goal is limited to showing that none of the arguments against diaphaneity considered below suffices to justify any such restriction, which lends some support to full diaphaneity. All that being said, for simplicity, I will use the terms 'selectionism' and 'diaphaneity' in the unrestricted sense.

Second, the history of diaphaneity, discussed at length by many philosophers (see e.g. Martin 1998, 2015; Stoljar 2004; Stoneham 2008; Van Cleve 2015; French 2018), is usually traced back to G.E. Moore (1922). In this paper, however, I am primarily interested in diaphaneity as a corollary of the primitivist-relationalist version of selectionism. Thus understood, diaphaneity entails that:

Difference Principle: Necessarily, if two experiences differ in phenomenal character, then they differ in character-constituting presented elements.

\footnotetext{
${ }^{4}$ It might be objected that it is possible to maintain even the most austere forms of relationalism without the commitment to selectionism and diaphaneity by suggesting that a single object can be perceived in many different ways. In Sect. 9, I argue that this is not a genuine alternative to selectionism and diaphaneity.
} 
Sameness Principle: Necessarily, if two experiences are alike in phenomenal character, then they are alike in character-constituting presented elements.

(French and Phillips 2020, 4; cf. French 2018, 152)

Third, diaphaneity is not equivalent to transparency. Consider two distinctions: metaphysical vs. phenomenological transparency (Gow 2016), and strong vs. weak transparency (Kind 2003). In the sense relevant to this paper, diaphaneity entails (but is not entailed by) metaphysical transparency (i.e. the claim that in having a perceptual experience one is only aware of the perceived items), and supports (but does not entail) phenomenological transparency (i.e. the claim that introspection of perceptual experience does not seem to reveal anything over and above the perceived items). On the other hand, diaphaneity understood as a corollary of primitivist-relationalist formulation of selectionism is antithetical to both strong transparency (i.e. the claim that it is impossible to attend directly to one's experience) and weak transparency (i.e. the claim that attending directly to one's experience is possible albeit difficult). This is because relationalism entails that the phenomenal character of perceptual experience is literally constituted by the perceived items, which means that attending to the perceived items amounts to attending to the experience itself. On this view, diaphaneity does not entail that one can only become aware of one's experience indirectly (i.e. in virtue of being aware of the perceived items), but it does entail that one can only become aware of one's experience's structural features indirectly (i.e. in virtue of being aware of the perceived items). I say more about this in Sect. 4.

Fourth, while diaphaneity entails that sameness and difference in phenomenal character is solely determined by sameness and difference in perceived items, it does not follow that the perceptual system does not participate in shaping the phenomenal character at all. To have that consequence, diaphaneity would have to be combined with negation of selectionism. According to selectionism, every perception reveals some aspects of the environment rather than another. Perceptual system determines which of those aspects are revealed on a given occasion. This is a substantial contribution to phenomenal character. That said, the conjunction of diaphaneity and selectionism entails that perceptual phenomenal character does not involve any mind-dependent phenomenal qualities, and this is what the critics deny.

Fifth, selectionism is a thesis about what it is like to perceive something, not about what it is like to be a subject that perceives something. What-it-is-like-ness in the latter sense is arguably determined by the totality of one's conscious mental states at the time of perceiving, of which what it is like to perceive something is only a part. For this reason, diaphaneity understood as a corollary of selectionism is not undermined by the fact that what it is like to be $\mathrm{S}$ who perceives $\mathrm{O}$ is partially determined by, say, the phenomenal character of an emotion $\mathrm{S}$ consciously feels at the time of perceiving $\mathrm{O}$.

\section{The Boundaries of Visual Experience}

Drawing on the works of Martin (1992), Richardson (2010) and Soteriou (2013), French $(2018,162-71)$ set forth a phenomenological argument against diaphaneity. Because French aims to persuade the relationalist to abandon diaphaneity, the 
argument assumes, in accordance with the relational view, that perceptual phenomenal character is at least partially constituted by aspects of the environment.

The argument starts with the observation that the phenomenal character of conscious visual experience involves spatial limitations. To explain why this is so, it is not enough to say that one can only see a limited amount of the visible aspects of the environment at a time. For the boundaries in question are not set by the visible aspects of the environment, nor are they set by the space these aspects occupy. They are set by the sensory limitations of the perceiver.

Here French appeals to the fact that visual experience has a cone-shaped visual field, the apex of which is where the eyes are. According to Richardson's interpretation of Martin's work, the visual field is a structural feature shared by all visual experiences. It is 'structural' in the sense of being common to all visual experiences, irrespective of what is experienced. As such, it is non-environmental (i.e. distinct form the perceived items), but nonetheless intrinsic to the phenomenal character of visual experience because it cannot be detached from it. What is more, the visual field is manifest in the phenomenology of visual experience, and evinces itself in the 'feeling' or 'seeming' (i) that there is always more to be seen than one actually sees at a given moment, and (ii) that, whether one is seeing some object or just an empty space, there is a region of space within which one can see something (Richardson 2010, 234, 238-39).

Now, since the limitation aspect of visual phenomenal character is constituted by the subject's sensory limitations (i.e. the visual field), it is not constituted by the perceived items. It follows that visual phenomenal character is not entirely constituted by the seen items, i.e. that diaphaneity is false (at least with respect to visual experience).

For this argument to work, the limitation aspect must constitute the phenomenal character in the same sense in which the environmental aspects constitute it. That is to say, the boundaries of the visual field must be phenomenologically manifest in visual phenomenology in the same way in which the seen items are. But they are not. While it is true that the boundaries are set by the subject and not by the environment, they are not seen in the same sense in which the environment is seen. In fact, they are not seen at all.

The boundaries of visual experience are supposed to be different from the seen items. Consequently, the awareness of the former is different from the awareness of the latter. If one could become aware of the boundaries in the same way in which one is aware of the items, the boundaries would reduce to the items. Since they are not so reducible, they are not perceived. They are just a feature of visual experience the perceiver discovers by way of comparing their current visual experience with the ones they had before.

On the relational view, visual awareness is an awareness of visible aspects of the environment. The latter constitute the phenomenal character of perceptual experience in the literal sense (i.e. they are proper parts of it). Since visual awareness is not an awareness of sensory limitations of visual experience, such limitations are not a proper part of the phenomenal character of seeing. 
This is not to deny that visual experience has a field. The point is only that the visual field does not contribute to visual phenomenology in the same way in which the seen items do. It may be constitutive of the phenomenal character in some sense, but certainly not in the sense in which the seen items constitute it. Hence French's argument fails due to the fallacy of equivocation.

To illustrate, imagine a possible world in which there is just one subject, call him Bud, who is about to open his eyes for the first time, and all there is to see is a bunch of red dots scattered across space. How many visual experiences does Bud have to undergo to find out about the environmental aspects and the limitation aspects of his visual experience? When it comes to environmental aspects, one experience should suffice. To find out that there is a red dot before him, it is enough if Bud looks just once. For all Bud knows after taking that single look, what he has seen could be all there is to see, in which case his visual experience would be spatially unlimited in this world. Hence it does not 'seem' to him at this point that there is more to be seen there. To find out about the limitation aspect of his visual experience, Bud has to undergo at least two experiences, and then compare them to each other. Only after looking for the second time (this time from a different perspective), can he learn that there was more to be seen when he was looking for the first time. Only then can he learn that he cannot see everything there is to see by looking just once, and thereby discover the limitation of his visual experience.

This thought experiment shows that the limitation aspect is not manifest in experience in the same way as the environmental aspects are. To find out about the dot, it suffices if Bud looks at it just once. To find out about his own visual limitations, he has to look at least twice, each time from a different perspective (i.e. look in two different directions, or with one eye closed at first, and then with both eyes open), learn that his first experience was not an experience of all there is to see, and then infer from all this that his vision is spatially limited. Visual boundaries are not visually manifest to Bud in the same way in which the dots are. They are perceptually available to him only indirectly. He can only become aware of them by comparing what he sees on various occasions.

According to Stoljar (2004, 372-73), assuming that perceptual model of introspection is false, being aware of intrinsic features of one's own experience in virtue of being aware of the perceived items still counts as an instance of direct awareness. For it does not consist in becoming aware of a fact in virtue of becoming aware of another fact. Instead, one becomes aware of facts about the intrinsic features of one's perceptual experience in the same way in which one becomes aware of facts about the perceived items, namely in virtue of being aware of the perceived items. Awareness of the intrinsic features of perceptual experience would count as indirect if it was based on some further facts, but there are no such further facts. Stoljar $(2004,384)$ concludes that

there is no way to defend the inference from the claim that I apprehend the intrinsic features of my experience by apprehending objects and properties represented in experience to the claim that I only indirectly apprehend those features. 
But one cannot become aware of the structural (or intrinsic) features of one's perceptual experience solely by becoming aware of the perceived items. One has to first become aware of facts about the ways in which the phenomenal characters of one's different experiences compare to each other.

The phenomenal character of seeing is constituted by what is seen. Since the limitation aspect of seeing is not seen, it does not constitute the phenomenal character, at least not in the relevant sense. Its role in shaping the phenomenal character is indirect, in that it determines which visible aspects of the environment constitute the phenomenal character. In this connection, the fact that visual experience has spatial boundaries is not only harmless to diaphaneity, but also supportive of selectionism. For the observation that each perceptual episode affords the perceiver a limited perspective on the world reinforces the claim that the architecture of the perceptual system selects which parts of the world are perceptually available to the perceiver on a given occasion (i.e. which parts of the world constitute perceptual phenomenal character on a given occasion).

If this is correct, the selectionist can and should turn the table on French by responding that he has failed to acknowledge the difference between (i) the way the visual field constitutes the phenomenal character and (ii) the way the perceived items constitute the phenomenal character.

\section{Blurry Vision}

The second phenomenological objection to diaphaneity concerns blurry vision. According to French (2014, 409-13), blurriness never occurs in and of itself; it always attaches itself to the presentational aspect of experience. One cannot just experience blurrily because blurriness is always a way of experiencing something, i.e. a modification of a presentation. On this view, blur is a phenomenologically manifest feature of perceptual phenomenal character that is not constituted by the perceived items, which is incompatible with diaphaneity. French $(2014,412)$ writes:

the blurriness involved in seeing blurrily does not even seem to be a presentational aspect of experience, yet the seeming involvement of objects, colours, and shapes in experience does seem to be presentational.

This point is not decisive because these seemings are better understood as cognitive states accompanying visual experiences rather than aspects of visual phenomenology (Gow 2019). Still, is it possible to explain blur without violating diaphaneity?

When I look at my glasses without having them on, it is not unreasonable to say that it is their objective blurry look that constitutes my current visual experience. For one thing, being familiar with this look helps me find the glasses when they are lost. For another, the blurry look of my glasses is not private because it is perceptually available to anyone who has the same vision defect as I do (or wears glasses inducing that defect). This suggests that the blurry look of my glasses is just as objective as their sharp look. On this view, both these looks are equally genuine 
visible aspects of the shape of my glasses. They are genuine in the sense that none of them is illusory or distorted.

Smith $(2008,203)$ has objected that this approach is phenomenologically inaccurate because it collapses the distinction between seeing blurrily and seeing a fuzzy object. That an object looks fuzzy to one does not necessarily mean that one sees it blurrily; it might just be a fuzzy object seen sharply. Conversely, an object might be seen blurrily despite being sharp. Furthermore, seeing blurrily usually does not dispose people to think that the object is fuzzy. Instead, people tend to withhold judgment regarding the shape of the object. If blurry vision revealed some otherwise unavailable properties of the object, it would make one prone to judge that the object is fuzzy, but this is not the case.

It is true that fuzziness and blurriness are two different properties. The conditions necessary for an object to look fuzzy differ from the conditions necessary for that object to look blurry. But it does not follow that blurriness is not a visible aspect of the environment.

Blurry vision takes various forms, which can be caused by various factors. Sometimes it results from a general drop in acuity caused by intoxication or fatigue, but most often it co-occurs with sharp vision (e.g. a distant object looks blurry when one focuses sight on some nearby object). Either way, when we say that an object looks blurry, we usually mean that it does not look sharp, where 'looking sharp' refers to the way that object looks in what we might call 'normal conditions' (i.e. roughly, from a certain distance, in daylight and in clear air, in the focus of attention of a non-intoxicated, non-fatigued human being with healthy sight).

These normal conditions are an anthropocentric idealisation. There is no single standard of visual acuity that enables one to see how things in the environment 'really' look. On the contrary, there is a widespread intra-personal, inter-personal, and inter-species variation in visual acuity. This gives rise to a paradox analogous to the paradox of colour variation discussed above. Even if we narrow the analysis to perception in a single species, the same object can look differently in terms of visual contrast to two subjects from the same distance, to the same subject from two different distances, to the same subject from the same distance on two different occasions. Add to this inter-species differences in vision and the number of possibilities multiplies. Who sees the 'real' contrast? And in what conditions? These questions generate scepticism about the idea that there is some objective standard of visual acuity that determines the way the shape of something really looks. According to the sceptic, these questions can only be answered by adopting an arbitrary standard (relative to the workings of a specific visual system in specific conditions). This scepticism is analogous to the scepticism behind colour pluralism, i.e. scepticism that there is some objective standard of colour vision that determines which colour a given surface really has. If one endorses the latter scepticism, consistency requires one to endorse the former. Or at least they owe us a reason why they endorse the latter but not the former.

Should we conclude that no one ever sees the world the way it really looks? Or should we arbitrarily fix some discrete standard of visual acuity that buys one a perfectly clear view of the world? Since both options are unacceptable, it seems reasonable to adopt the selectionist position, according to which all levels of visual acuity 
reveal different objective aspects of the environment. On this view, the fact that my glasses have this look when seen in these circumstances and that look when seen in those circumstances does not show that my vision distorts reality in any of the cases. The glasses have both looks (and many more), and which of those one sees turns on the circumstances of seeing ${ }^{5}$.

Blurry vision does not reduce to seeing 'merely determinable locational features' (French 2016, 397) because that would mean that seeing blurry boils down to seeing less of the environment than we do in normal conditions. And yet seeing how an object looks from a blurred perspective puts one in a position to learn something new about that object, i.e. to discover its blurry look, i.e. a genuine visible aspect of its shape. While familiarity with blurrier looks of an object usually has less epistemic value than familiarity with its sharper looks, in some cases it might be significant, e.g. due to aesthetic reasons. Hence seeing blurry is not always an obstacle to cognition.

That said, everyday conversations about blurry vision are not simply about the ways things look. They are about the ways things look in relation to the anthropocentric standard of normal conditions. Consequently, the ability to distinguish a blurry experience from a sharp experience (as well as the ability to distinguish a blurry experience of a sharp object from a sharp experience of a fuzzy object) is a matter of knowledge about how various things look in various conditions, and how the way something looks on a given occasion relates to the way it looks in normal conditions. It is not an example of that knowledge that the blurry look of my glasses is somehow superimposed on their objective sharp look by my short-sightedness. It $i$ an example of that knowledge that my glasses look blurry when seen from a shortsighted perspective and sharp when seen with a healthy (or corrected) pair of human eyes ${ }^{6}$.

Compare this to Mizrahi's (2006, 288-89; cf. Kalderon 2011a) suggestion that chromatic adaptation (i.e. enervation of colour receptors due to prolonged stimulation) does not result in colour illusion. Instead, previously unseen colours of the perceived object become perceptually available. For instance, when the eyes are exposed for a long time to a long-wavelength light (e.g. red), the subsequently perceived scene will appear more greenish. While it might seem absurd to insist that the resulting experience presents things the way they really are, Mizrahi supports this hypothesis with a persuasive example from everyday life. It is a common practice at crime scenes to use filters that block light of certain wavelengths. Often this is the

\footnotetext{
5 An anonymous referee has pointed out that my proposal is counterintuitive with respect to the way people tend to think about blurry vision in every-day situations. This is true, and it can be used against one of the motivations behind relationalism, according to which relationalism is superior to other theories of perception when it comes to being faithful to what common sense tells us about perceptual experience. I admit that the relationalist who accepts my account of blurry vision has to discard that motivation. But I do not see this as a high cost, because common sense is itself a highly controversial notion, and whatever conception of common sense is adopted, all theories of perception are likely to violate it in some respect or other.

${ }^{6}$ This account of blurry vision constitutes an alternative reply to Cassam's objection against Campbell's exposition of relationalism (Campbell and Cassam 2014; French 2016).
} 
only way to make fingerprints and small amounts of body fluids visible. The resulting colour experience is not considered illusory. On the contrary, it is approved in court as a perfectly legitimate source of evidence.

If this explanation of chromatic adaptation is viable, blurry vision can be explained along the same lines. On this view, blurry vision renders some aspects of the environment invisible while rendering some of its other aspects visible. This accords with the fact that perception is partial, i.e. that one cannot see the entire environment from a single point of view (Kalderon 2007; Campbell 2009).

My diaphaneity-friendly account of blur ties up with the diaphaneity-friendly account of the visual field defended above. To see why, consider Skrzypulec's (Skrzypulec 2021a) proposal that visual experience has both exteroceptive and interoceptive content, and that blurriness-related phenomenology interoceptively represents the state of the visual system (i.e. the acuity of vision in relation to eye focus). The rationale behind this view is that blurry vision provides prima facie justification for beliefs about the visual system and motivates action towards the eyes (e.g. blinking, rubbing eyes). While Skrzypulec is right that blurry phenomenology can be indicative of the state of the visual system, it does not follow that I see the state of my visual system just by seeing blurry ${ }^{7}$. Instead, I can infer the acuity of my visual system by comparing the way my glasses look when I see them with my naked eyes to the way they looked to me when I saw them having my contact lenses on.

To be clear, I am not denying that seeing blurrily can be an indication that something is wrong with one's visual system. My point is only that the state of one's vision is not simply seen when one sees blurry. On my proposal, when S sees blurrily, things look to $\mathrm{S}$ different than they usually look to $\mathrm{S}$. As a result, $\mathrm{S}$ uses their knowledge about how things look in various circumstances to infer that the potential reason why things look different is that their vision malfunctions.

My reply to Skrzypulec is analogous to the one given to French in Sect. 4 because both Skrzypulec's account of blur and French's account of the visual field share the same defect, i.e. they over-intellectualize perceptual phenomenal character. The phenomenal character of a perceptual experience is distinct from the truths one can come to know in virtue of having that experience. The fact that I can come to know certain truths about the boundaries of my visual field (or about the acuity of my vision) thanks to having a certain visual experience does not entail that those truths are somehow embedded in the phenomenal character of that experience. Perceptual experience cannot tell me any truths about itself (nor about anything else) because it is silent (Travis 2004). To think otherwise is to conflate seeing things with seeing that something is the case (Travis 2018,344$)^{8}$.

\footnotetext{
7 Skrzypulec claims that his proposal is consistent with metaphysical transparency because he regards the visual system as a mind-independent object. It goes without saying that the latter claim is controversial.

${ }^{8}$ One might object that my reply to French and Skrzypulec presupposes a contentious position about the perception/cognition distinction. While defending the latter is beyond the scope of this paper, the mere fact that the objector is likely to move the discussion into that area reinforces my point that diaphaneity cannot be refuted on purely phenomenological grounds.
} 
To sum up, diaphaneity cannot be easily discarded by phenomenological considerations, at least not without adopting some controversial theoretical assumptions. In the following sections, I argue that the same point applies to empirical arguments against diaphaneity.

\section{Attentional Variation}

Block (2010) contends that perceptual phenomenal character cannot be explained in terms of the perceived items because the relation between the phenomenal character and the perceived items is contingent. In support of this claim, Block adduces a large body of empirical evidence, at the core of which is the study by Carrasco et al. (2004). The subjects were presented with a Gabor patch (a grid of sinusoidal luminance stripes) to either side of the fixation point and asked to report the orientation of whichever of the patches had a higher contrast. In some trials, the attention of the subjects was cued to one of the patches. In such cases, the subjects were more likely to report the orientation of the attended patch when its contrast was equal to, or slightly lower than, the contrast of the unattended patch.

According to Block, this shows that attention increases the perceived contrast. Other studies cited by Block applied the same paradigm to different variables, and their results suggest that not only the perceived contrast, but also saturation, size, spatial frequency, gap size and flicker rate can be modulated by attention.

Block believes that this cannot be explained by suggesting that attention modifies perceptual phenomenal character by selecting which features of the environment are perceived on a given occasion. Since the perceived item has only one contrast, it cannot be said that attention selects which contrast of that item one perceives. On Block's preferred explanation, the phenomenal character of perceptual experience is a kind of 'mental paint', i.e. an intrinsic feature of experience that carries its representational content (Block 1996). Mental paint represents the perceived items, but it can vary independently of them. This is typically illustrated with thought experiments about inverted spectrum (e.g. the possibility that one's experiences of red and green swap their phenomenal characters). The mental paint view easily accommodates the possibility that shifts in attention can modify perceptual phenomenal character without any change in what is perceived.

In response to Block, Brewer (2013) insists that the selectionist explanation can be applied to the evidence at issue. Brewer's reply trades on the distinction between thin and thick looks. To say that an object $\mathrm{O}$ thinly looks $\mathrm{F}$ to the subject $\mathrm{S}$ is to say that, when perceived by $\mathrm{S}$ on a given occasion, $\mathrm{O}$ exhibits visually relevant similarities with paradigm exemplars of $\mathrm{F}$. When $\mathrm{S}$ not only sees $\mathrm{O}$ but also sees that $\mathrm{O}$ is $\mathrm{F}$ (i.e. recognises $\mathrm{O}$ as an instance of $\mathrm{F}$ ), $\mathrm{O}$ not only thinly but also thickly looks $\mathrm{F}$ to $\mathrm{S}$. Hence recognition is always accompanied with a phenomenological change.

A single object has plenty of thin looks, in that it visually resembles many things at the same time. It exhibits visual similarities to paradigm exemplars of $\mathrm{F}$, $\mathrm{G}, \mathrm{H}$, and so on. Recognizing an object as an instance of one of those categories is partially a matter of focusing on some of those thin looks while ignoring others. When $\mathrm{O}$ is recognised as an instance of a category, say F, it still thinly looks 
to $\mathrm{S}$ in all those ways $(\mathrm{F}, \mathrm{G}, \mathrm{H} \ldots)$, but now it also thickly looks to $\mathrm{S}$ in only one way $(\mathrm{F})$.

Brewer $(2013,430)$ applies this framework to Carrasco and colleagues' results:

A given Gabor patch viewed from a fixed point of view and in fixed circumstances has visually relevant similarities with paradigms lying in a range around its actual intensity. Greater attention involves greater discrimination with respect to the difference between the dark and light bands and hence induces registration of similarities with paradigms of greater intensity. Less attention involves less discrimination between light and dark bands and hence induces registration of similarities with paradigms of less intensity.

Brewer $(2013,431-32)$ is also quite explicit that the interpretation he offers is a form of selectionism:

what is phenomenally salient to us about the particular worldly objects of our acquaintance also depends upon our interest and attention. But this simply serves to select among what is there to be seen, on the present proposal, resulting in the registration of some and not other visually relevant similarities. [...] there is at least a sense in which it does not even seem to be the experience of an objective variation in the stimulus itself. [...] on the other hand, this comes out in the extent to which variation in registration is evidently a variation in the recognition or registration of what is there anyway: a selection among different aspects of the stimulus itself. In one sense, the stimulus looks different, attended versus unattended, and in another it does not.

Brewer's explanation is clearly consistent with diaphaneity and selectionism. But does it explain the evidence better than Block's mental paint explanation? Brewer's position is controversial in that it entails that the contrast of a single object has multiple visible aspects. The idea is that a Gabor patch can simultaneously thinly look both $22 \%$ and $28 \%$ contrast while thickly looking $28 \%$ contrast. According to Beck (2019a, 621-23), this proposal fails to distinguish competing from non-competing looks. Looks $\mathrm{F}$ and $\mathrm{G}$ compete if nothing can look both $\mathrm{F}$ and $\mathrm{G}$ to a normal perceiver under normal conditions. Since the patches in the Carrasco and colleagues' study were perceived by normal perceivers in normal conditions, their contrast looks were competing. Nothing looks both $22 \%$ and $28 \%$ contrast to a normal perceiver under normal conditions.

However, it is far from obvious that the conditions in that study were normal. As Beck and Schneider (2017) point out, Carrasco and colleagues' results do not unequivocally show that attention changes the appearance of the stimulus by increasing its contrast. They suggest that attention merely increased the salience of the stimuli, which was then mistaken for a boost in contrast by the subjects. The probability of this mistake was very high due to uncertainty-generating conditions of the task.

Considering that the stimuli were presented to the subjects for a fraction of a second and the subjects had only one second to respond, this is a plausible 
interpretation. What makes it even more compelling is the fact that the attentional effect vanishes when the experimental paradigm is changed. When the subjects were asked whether the stimuli have the same intensity or not (instead of being asked which of the two stimuli is more intense), whereas the stimuli and the rest of the procedures were just as in the original Carrasco and colleagues' study, no effect of attention was observed (Schneider and Komlos 2008). The same problem affects other studies cited by Block. In all those experiments, the perceived intensity was likely to be confounded with a decision bias.

According to Beck and Schneider $(2017,486)$, their interpretation does not vindicate any selectionist account such as Brewer's. For it remains incumbent on the selectionist to identify an objective feature of the Gabor patch that is rendered visible thanks to an increase in salience caused by attention, and J. Beck and Schneider are sceptical about that. They explain attentional variation by postulating 'mental primer', a qualitative feature of perceptual experience caused by conscious attention. Mental primer is irreducible to the perceived items (like mental paint) but does not represent anything (unlike mental paint). Mental primer is also different from qualia because it has a function. It realizes functional salience, i.e. increases the probability that the stimulus will be selected for action and cognition (Beck and Schneider 2017, 484, 489-90).

Beck and Schneider (2017, 483-84) argue that functional salience is distinct from phenomenal salience (i.e. the phenomenal character of consciously attending) because (i) attention can occur unconsciously, and (ii) the salience of a stimulus causally explains why the stimulus becomes attended, which means that salience precedes attention. Recall that J. Beck and Schneider's interpretation of Carrasco and colleagues' experiments is that attention increases salience. I take it that the stimulus $\mathrm{O}$ is already salient to some extent before it becomes attended. Becoming attended does not render $\mathrm{O}$ salient; it just increases O's salience.

At this point, however, it seems that positing mental primer is unnecessary. Why not attribute the pre-attentional salience of $\mathrm{O}$ to its thickly looking $\mathrm{F}$ ? And why not think that the increase of the probability that $\mathrm{O}$ will be selected for action and cognition due to its being consciously attended (the alleged function of mental primer) is in fact a matter of O's even thicker looking $\mathrm{F}$ due to its becoming consciously attended?

The selectionist can offer the following alternative to mental primer. When $\mathrm{S}$ recognises $\mathrm{O}$ as $\mathrm{F}, \mathrm{S}$ 's associations and beliefs concerning $\mathrm{O}$ become actuated. Consciously attending to $\mathrm{O}$ arguably amplifies that process. On the phenomenological level, S's recognising $\mathrm{O}$ as F results in O's thickly looking $\mathrm{F}$ to $\mathrm{S}$, which in turn renders O's F-ness salient to $\mathrm{S}$. That salience attracts attention. When consciously attended, an F-looking $\mathrm{O}$ will strike $\mathrm{S}$ as an instance of $\mathrm{F}$ more than before (i.e. it will make $\mathrm{O}$ look $\mathrm{F}$ to $\mathrm{S}$ even more thickly, and thereby render O's F-ness even more salient).

One might object that functional salience can be unconscious, whereas thickly looking F is supposed to be conscious. However, Brewer's account can be modified by allowing for unconscious phenomenal character, and unconscious thin and thick looks (see Sect. 8). 
In contrast to mental paint view, Brewer's account does not hinge on Block's interpretation of the evidence. It can be adapted to Beck and Schneider's interpretation. What is more, it is an advantage of Brewer's view that it explains attentional variation in accordance with selectionism and diaphaneity. For if mental paint (or mental primer) are involved in perceptual phenomenal character, it should be possible to shift attention from the perceived items to the intrinsic properties of perceptual experience. However, as Weksler et al. (2021) point out, that possibility is at odds with the current state of art in the neuroscience of sensory attention.

The relevant theories construe sensory attention as a modulation of the neural basis of perception $(\mathrm{N})$, which leaves no room for attention to mental paint (or mental primer, for that matter). For example, suppose that sensory attention consists in shrinking the Receptive Field (a part of the retina to which the neural basis of perception responds) by modulating $\mathrm{N}$. While such a change clearly modifies the sensory access to perceived items, there is no reason to believe that it adds any additional qualitative layer to perceptual phenomenal character.

The topic of attentional variation is complex, and much more would have to be said to make a compelling case for the claim that selectionism explains that phenomenon better than the competition. Still, contrary to what the critics have suggested, it is far from obvious that such an account is a non-starter.

\section{Irregular Grounding}

Pautz (2017, forthcoming) argues that diaphaneity is undermined by a juxtaposition of empirical findings in psychophysics and neuroscience. On the one hand, qualitative similarity is poorly correlated with external (i.e. extra-dermal) physical properties. On the other hand, qualitative similarity is well-correlated with internal (i.e. neural) physical properties. Pautz adduces three examples of this.

First, while the phenomenal character of seeing a blue-looking ball is more similar to that of seeing purple-looking grapes than that of seeing a green-looking leaf, the reflectance of the blue-looking ball happens to be more similar to that of the leaf than that of the grapes. This indicates that differences and similarities in reflectance and illumination fail to predict differences and similarities in phenomenal character, whereas differences and similarities in neural activity do predict differences and similarities in phenomenal character (MacAdam 1985; Brouwer and Heeger 2013; Bohon et al. 2016).

Second, the phenomenal character of smelling R-limonene resembles that of citral more than that of R-carvone even though R-limonene is much more similar to $\mathrm{R}$-carvone than to citral in terms of chemical structure. And yet the neural activity associated with smelling R-limonene resembles the one associated with smelling citral more than that associated with smelling R-carvone. It turns out that olfactory experiences, just as visual experiences, are better correlated with patterns of neural activity than with physical properties of the environment (Margot 2009; Howard et al. 2009).

Third, there can be large categorical changes in audible qualities, accompanied with corresponding changes at the level of neural activity, that occur without any 
corresponding physical changes in the auditory stimulus (Goldstein 2009; Chang et al. 2010). Yet another case of 'good internal correlation' and 'bad external correlation'.

The evidence clearly suggests that the qualities comprising the phenomenal character of perceptual experience fall into a different resemblance-order than the physical properties of the perceived items. Pautz draws two conclusions from this. First, phenomenal qualities are not identical to external physical properties. For if they were, phenomenal qualities should fall into the same resemblance order as external physical properties, which, as it turns out, is not the case. Second, it is implausible that phenomenal qualities are distinct from external physical properties but nonetheless somehow grounded in the latter. For, given the bad external correlation and the good internal correlation, such grounding relation would have to be completely irregular and unsystematic. It would be 'just a quirk of reality with no explanation' (Pautz 2017, 27-28).

Pautz does not go as far as to say that reducing phenomenal qualities to physical properties necessarily requires that both types of properties fall into the same resemblance order. But he does think that reduction is highly implausible if both types of properties fall into different resemblance orders. That would require irregular grounding, and in Pautz's opinion 'it goes without saying' that we should avoid irregular grounding (Pautz forthcoming, 15). Although I am not entirely convinced of this explanatory norm, I follow it here for the sake of the argument because I want to show that selectionism and diaphaneity are not undermined even if Pautz is right.

Suppose for a moment that the norm is wrong, and irregular grounding is tolerable. This paves the way for objectivist reductionism, according to which phenomenal qualities can reduce to external physical properties despite the difference in resemblance orders. However, it also allows the selectionist to retreat to their previous position, according to which phenomenal qualities are distinct from, but somehow grounded in, external physical properties. In fact, rejecting the norm still leaves objectivist primitivism in a better position than objectivist reductionism, because the difference in resemblance orders provides the primitivist with an additional reason to resist the reduction of phenomenal qualities to external physical properties.

By interpreting the evidence in accordance with the norm, Pautz formulates two arguments against the relational theory of perception. The first argument is an inference to the best explanation. A brain-based theory of perceptual phenomenal character can explain the evidence in question without the appeal to irregular grounding. If the phenomenal character is realized by brain activity in response to external stimulation, no systematic correlation between phenomenal qualities and external physical properties is required. By contrast, relationalism appears to be committed to irregular grounding, at least insofar as it is committed to something like diaphaneity. On this view, phenomenal qualities are just sensory qualities (or aspects thereof) grounded in external physical properties. But the evidence suggests that the nature of such grounding relation would have to be completely random. Therefore, we should opt for the brain-based view and reject relationalism (Pautz forthcoming, 9).

The second argument trades on a Twin Earth thought experiment. Consider a counterfactual counterpart of yourself that is identical to you in every respect except for one thing: their neural response to R-limonene resembles their neural response to 
R-carvone more than their neural response to citral (which, as the evidence suggests, is the exact opposite to how things stand in the actual world). Given the evidence that the neural response is a much better predictor of the phenomenal character than the physical structure of the environment, it seems that R-limonene should smell differently to your counterpart than it does to you. And yet relationalism, at least insofar as it is committed to diaphaneity, seems to predict that R-limonene smells the same to you and to your counterpart because you are both sniffing the same chemical substance in the same circumstances. In the light of the evidence adduced by Pautz, this is a wrong prediction. Construing perception in terms of selectionism does not help because your perceptual systems select the same physical features of the environment (Pautz forthcoming, 17-20). It actually exacerbates the problem, since the view that each reflectance grounds infinitely many colours entails that there are infinitely many instances of irregular grounding (Pautz forthcoming, 27-28) ${ }^{9}$.

The actual target of these arguments is diaphaneity. It is no accident that philosophers sympathetic to relationalism tend to respond by distancing themselves from diaphaneity (see Sect. 9). And conversely, if diaphaneity is true, there must be something wrong with the arguments. Indeed, I think that there is a lacuna in both arguments. According to diaphaneity, perceptual phenomenal character is entirely constituted by the perceived items. But it does not follow that the phenomenal character is grounded in external physical properties. And yet the arguments require that entailment to be true. Phenomenal qualities cannot be irregularly grounded in external physical properties if they are not grounded in any physical properties at all.

This observation does not save reductionist selectionism. As mentioned in Sect. 2, the latter identifies colours with reflectance properties. If colour experience is wellcorrelated with neural properties and poorly correlated with reflectance properties, reductionist selectionism is in jeopardy.

Things are different when it comes to primitivist selectionism, however. Take colours for example. Primitivism construes them as non-physical, i.e. non-identical to reflectance properties (nor any other physical property). Although primitivist selectionists tend to argue that colours supervene on physical properties of the perceived items (see e.g. Allen 2016, 75), this is optional. Neither primitivism nor selectionism entails that colours depend on reflectance properties for their existence. To keep primitivism compatible with vision science, it suffices to say that colours depend on reflectance properties for their visibility. The fact that a coloured object has reflectance properties makes it possible for subjects endowed with appropriate visual systems to see its colours. But it does not follow that the object has its colours in virtue

\footnotetext{
${ }^{9}$ On top of that, Pautz claims that denying that the evidence he adduced undermines relationalism is tantamount to saying that relationalism is 'empirically indefeasible' which he thinks is 'an absurd stance' because relationalism is at least in part 'an empirical thesis about how experience is to be integrated with the natural world' (Pautz forthcoming, 25). I disagree. Relationalism is a position in metaphysics of perception, and it is common knowledge in philosophy that metaphysical claims do not admit of straightforward empirical disconfirmation. Empirical evidence certainly does matter for deciding which metaphysical position is preferable. But to argue that a metaphysical claim can be undermined by an empirical experiment is to endorse scientism, which itself is a highly contentious metaphilosophical attitude.
} 
of having its reflectance properties ${ }^{10}$. As far as primitivism is concerned, the object might have two types of properties, physical and non-physical, none of which is more fundamental than the other ${ }^{11}$.

Importantly, I am not suggesting that we see colours by seeing physical properties (which would render colour perception indirect). We do not see photons striking the retina, reflectance properties, nor their microphysical realizers. The suggestion is rather that all these physical properties enable us to see the object's colour, a quality that that object has independently of having its physical properties.

The fact that the phenomenal character of colour experience is well-correlated with neural properties and poorly correlated with reflectance properties does not entail that the phenomenal character of colour experience is poorly correlated with mind-independent non-physical properties. And it is far from clear that reflectance properties must fall into the same resemblance-order with colours qua mind-independent primitive non-physical properties to enable the visibility of the latter. Given the good correlation between colours and neural properties, it might be the case that factors such as reflectance and illumination render a certain amount of an object's colours visible, and the neural activity selects which of those colours ultimately gets seen on a given occasion.

This version of primitivist selectionism is not undermined by the arguments put forward by Pautz. It does not require irregular grounding because it does not claim that the phenomenal character of colour perception is grounded in external physical properties. Neither does it predict that R-limonene smells the same to you and your counterfactual twin whose neural response to that substance is different from yours. For on this view the neural activity responsible for olfactory perception does not select external physical properties of the perceived object. It selects non-physical properties (i.e. smells qua sensory qualities) in virtue of the fact that the perceived objects have certain physical properties that enable perception of those qualities.

For this reply to work, it is not necessary to show that sensory qualities really are non-physical properties rendered perceptually accessible to us by physical properties of their bearers. It suffices to show that the evidence adduced by Pautz admits of this interpretation. I see no obvious reason why not.

An anonymous referee has objected that there is an internal tension in my reply to Pautz. Given that I follow Pautz in assuming that irregular grounding should be avoided because it would be 'a quirk of reality with no explanation' if phenomenal qualities were grounded in external physical properties, why don't I think that it would be 'a quirk of reality with no explanation' that the visibility of phenomenal qualities is grounded in external physical properties?

Let me respond using colour perception as an example. It is an empirical fact that certain physical properties have to be instantiated (both in the subject and in the

\footnotetext{
${ }^{10}$ Put differently, it is conceivable that an object has colours but lacks reflectance properties (cf. Allen 2016, 77).

11 It might be objected that my proposal renders colours causally inefficacious. But the objection presupposes the mechanistic conception of causation, which is optional and controversial. As Allen (2016, 102-4) points out, causal powers of colours are best understood in terms of difference-making, not in terms of mechanistic processes. Allen's point spreads to other sensory qualities.
} 
environment) for colour perception to occur. The evidence adduced by Pautz suggests that external physical properties do not settle which colour is perceived. But the evidence does not show that external physical properties play no role in colour perception. It does not rule out that, on each occasion of colour perception, which colour is perceived is co-determined by external and internal physical properties. And that is all I need for my reply to work. According to my proposal, there are colours in the environment, and when certain physical properties are instantiated, one becomes perceptually aware of some of those colours. There is nothing mysterious in this account. The finding that colours fall into different resemblance order than external physical properties does not make my account incomprehensible because on my account external physical properties (i) do not determine what colours are, and (ii) render colours visible if and only if certain internal physical properties are instantiated that do fall into the same resemblance order as colours. Of course, one might find this view counterintuitive and/or inconsistent with some claims one strongly believes to be true, but the view is not unintelligible. The proposal would be unintelligible (or at least very difficult to comprehend and motivate) if it claimed that external physical properties (i) determine what colours are, and/or (i) render colours visible independently of what internal physical properties are instantiated.

This brings me to the second issue raised by an anonymous referee. Assuming that my reply works, could the objectivist reductionist reply in the same way? I do not think so. The objectivist reductionist claims that phenomenal qualities reduce to external physical properties. But if these two types of properties fall into different resemblance orders, it is mysterious how the reduction is supposed to work. In the case of objectivist reductionism, the problem is not just that the view under consideration is counterintuitive or inconsistent with something we believe. The main problem is that we have merely superficial understanding of what the view says, which is much worse.

At this point, it might be objected that the brain-based view provides a more compelling interpretation of the evidence than objectivist primitivism. If the phenomenal character is strongly correlated with neural properties and badly correlated with reflectance properties, what reason is there left to think that the phenomenal character is comprised of mind-independent qualities?

First, my proposal neatly explains why the phenomenal character of shape experience is much better correlated with external physical properties than the phenomenal character of colour experience (Logue 2012, 215-16; Pautz forthcoming, 33). For this is only to be expected if colours, contrary to shapes, are not physical properties.

An anonymous referee suggests the following response on behalf of the brainbased theorist: "If the primitivist can posit a primitive fact that colours are such that they can be seen when certain physical properties are instantiated, I can posit a primitive fact that the phenomenal character of shape experience is much better correlated with external physical properties than the phenomenal character of colour experience.'

Still, I think that the appeal to a primitive fact is more innocent in the case of objectivist primitivism. For the objectivist primitivist, secondary qualities such as colours are on a par with primary qualities, in the sense that they are considered fundamental features of the world, along with mass and location. On this view, it is 
expectable that some facts about secondary qualities will be primitive. For the brainbased theorist, by contrast, phenomenal qualities are not fundamental constituents of reality; they are clusters of physical properties produced in the brain in response to some other cluster of physical properties occurring in the environment. It seems much more suspicious to say that it is a primitive fact that $<$ the cluster to which the phenomenal character of shape experience reduces $>$ is much better correlated with external clusters than $<$ the cluster to which the phenomenal character of colour experience reduces $>$. After all, these clusters are not fundamental features of reality; they are high-level complexes of physical properties. Appealing to primitive facts in the explanation of how various high-level complexes of physical properties are related is arguably more suspicious than appealing to primitive facts in characterizing fundamental features of reality.

Second, primitivist selectionism preserves colour objectivism, and thereby 'does justice to the phenomenology of colour experiences in locating colours exactly where they appear to be, that is, on the surfaces of objects' (Mizrahi 2006, 286). A similar point can be made about smells and sounds. While the brain-based view construes perceptual experience as an internal alteration of the subject, selectionism emphasizes that perceptual experience is first and foremost a mode of sensitivity to the environment (Kalderon 2018).

While not everyone accepts these desiderata, questioning them shifts the debate into a completely different dimension. It turns out, unsurprisingly, that the status of selectionism does not depend exclusively on empirical evidence, but also on the underlying assumptions determining how the evidence is interpreted. What lesson is there to be drawn from the evidence turns on underlying metaphysical assumptions about the nature of phenomenal qualities, as well as on meta-philosophical assumptions concerning what makes a satisfactory philosophical explanation.

\section{Unconscious Perception}

One of the main threads in contemporary philosophy of perception concerns the plausibility and ramifications of the following hypothesis:

(UP) Mental episodes of the same fundamental kind as ordinary conscious seeing can occur unconsciously.

UP is supported by a great deal of evidence (see e.g. Block 2011, 2012; Breitmeyer 2015; Prinz 2010; Weiskrantz 1986). Unconscious seeing is claimed to occur in certain clinical cases (e.g. blindsight, unilateral neglect, visual agnosia), as well as in experimentally induced cases (e.g. priming, continuous flash suppression). In all these cases, the subjects report no consciousness of a visual stimulus even though objective measures indicate that the latter has influenced their behaviour and/or brain activity. While the move from that evidence to UP has been questioned (Phillips 2018; 2016a), the opposition to UP itself rests on some controversial assumptions (Berger and Mylopoulos 2019, Zięba 2019), which means that the hypothesis should be taken seriously. 
Beck (2020) argues that UP constitutes a reason to reject selectionism and diaphaneity. Compare seeing a red dot consciously and unconsciously. A straightforward explanation of the difference between the two cases is that conscious seeing of the dot has a phenomenal character, whereas unconscious seeing of the dot does not. If so, there can be pairs of perceptual episodes such that the same item is perceived in both cases and yet there is a difference between them in phenomenal character. This undermines diaphaneity because the latter is incompatible with the possibility that two perceptual episodes differ with respect to phenomenal character even though the same item is perceived in both cases. Since selectionism entails diaphaneity, the inconsistency between diaphaneity and UP entails that selectionism is also incompatible with UP.

But diaphaneity is not inconsistent with UP. Quite on the contrary, diaphaneity predicts and supports UP. If diaphaneity is true, whatever has the property of being a constituent of the phenomenal character of a perception, it has that property contingently (it is not essentially a property of a mental state). It follows that perceptual phenomenal character is entirely mind-independent, which makes it entirely consciousness-independent as well. Consequently, diaphaneity entails the logical possibility of unconscious perceptual phenomenal character. And while the latter does not yet entail UP, it introduces a conception of perceptual phenomenology according to which it makes perfect sense to interpret the evidence mentioned at the beginning of this section in terms of UP.

To illustrate, compare two perceptual episodes: (a) S sees O consciously, and (b) $\mathrm{S}$ sees $\mathrm{O}$ unconsciously. Suppose that there can be a difference between (a) and (b) that goes beyond the fact that the former is conscious while the latter is not. The idea is that the episode (a) is not just a conscious copy of the episode (b), because becoming conscious made (a) inherently different from (b). Skrzypulec (2021b) has recently argued that such a difference might exist between conscious and unconscious colour perception. If this is true, it is a substantial reason to be sceptical about UP (the strength of the reason turns on the significance of the difference). But it is only true if diaphaneity is false. For if diaphaneity is true, consciousness cannot change a perceptual episode like that. Diaphaneity rules out the possibility that perceptual phenomenal character or perceptual content can change just by becoming conscious. Therefore, UP is more plausible if diaphaneity is true.

O. Beck's argument presupposes, in accordance with the tradition, that there is no such thing as unconscious phenomenal character. But this traditional assumption is disputable. Marvan and Polák (2017) present a series of arguments to the conclusion that phenomenal character does not depend on consciousness for its existence ${ }^{12}$. Interestingly, one of those arguments is based on empirical results that are sometimes mentioned as the strongest available evidence for UP, namely studies suggesting that colours can be seen unconsciously (Boyer et al. 2005; Railo et al. 2012; Ro et al. 2009; Norman et al. 2014; Moutoussis and Zeki 2002). If colours constitute the phenomenal character of colour perception, and colours can be seen unconsciously,

\footnotetext{
12 The idea of unconscious phenomenal character is inspired by Rosenthal's insistence that the existence of mental qualities does not depend on their being conscious (Rosenthal 2010).
} 
the phenomenal character of colour perception is consciousness-independent. If a perception is conscious, its phenomenal character determines what it is like to have that perception. Because the phenomenal character of unconscious perception is not conscious, there is nothing it is like to undergo unconscious perception ${ }^{13}$.

If perceptual phenomenal character can be unconscious, it is not true that consciously seeing a red dot and unconsciously seeing the same dot constitute a pair of perceptual episodes that differ in phenomenal character despite being the same with respect to what is perceived.

However, as I have argued in the previous section, the evidence adduced by Pautz suggests that selectionism is only viable if coupled with primitivism, whereas Marvan and Polák's view is embedded in a brain-based view of phenomenal character. They claim that conscious perceptual experience results from an interaction between two neural mechanisms: one generates the phenomenal character, the other renders that phenomenal character conscious. On that view, unconscious perception occurs when the second mechanism malfunctions (Polák and Marvan 2019, 2). Is it possible to implement the idea of unconscious phenomenal character into the relationalist-primitivist framework?

Some relationalists might respond 'no'. The orthodox formulation of relationalism construes perception as a 'modification of consciousness' by conscious acquaintance with a mind-independent object (Brewer 2011, 92). This raises a worry: how could this acquaintance be sometimes conscious and sometimes not? How could unconscious perception instantiate acquaintance with a mind-independent object if that object makes 'no contribution to the subject's conscious perspective on the world' (Phillips 2018, 472)? It would seem that 'unconscious acquaintance' is an oxymoron, as it appears to imply that the subject can be 'unconsciously conscious' of the environment (French and Phillips forthcoming).

This problem is not as serious as it may seem. Consider the core of the relational view, i.e. the claim that the phenomenal character of perceptual experience is constituted by the mind-independent object. Neither does this claim entail that perceptual phenomenal character is inherently conscious, nor does it follow from it that perception and consciousness cannot dissociate. The core of relationalism is silent as far as UP is concerned (cf. Zięba 2019).

Relationalism holds that what it is like to consciously perceive an object is determined by the properties that object has independently of being perceived. Since these properties are mind-independent, they are consciousness-independent as well. As the constituents of perceptual phenomenal character, they are phenomenal qualities. But they are not phenomenal in the sense of being inherently conscious. They are phenomenal in the sense of determining what it is like to perceive them when they are consciously perceived. Now add to this the possibility of a mental episode that resembles conscious perception in almost every respect (e.g. it guides action and causes belief formation), except that there is nothing it is like to be in it. Assuming that what-is-like-ness is a mark of consciousness, our hypothetical episode

13 Coleman $(2020,69-71)$ defends the same view with regard to phenomenal character of pain and suffering. 
clearly instantiates perception without consciousness. What else could it be? Again, the core of relationalism does not give us any reason to deny that perceptual relation could occur unconsciously, which is partially because it does not entail that perceptual phenomenal character is inherently conscious.

As far as I can tell, the only way to resist this point is to supplement relationalism with the claim that relationalism pertains to perception qua personal state whereas evidence for UP only justifies countenancing unconscious perception qua sub-personal state (French and Phillips forthcoming; Phillips 2018). This would suggest that conscious perception and unconscious perception are not perceptions in the same sense of 'perception'.

But this is not convincing because the supplementary claim (i) is distinct from relationalism, which makes it optional for the relationalist; (ii) rests on the controversial assumption that the distinction between personal and sub-personal levels of explanation maps onto a corresponding distinction between personal and sub-personal states (Bermúdez 2000; Wong 2014; Drayson 2012); (iii) undermines UP and thereby does not really lend itself to salvage O. Beck's argument.

\section{Objectivism Without Selectionism?}

Even if selectionism and diaphaneity emerge unscathed from the criticism discussed above, it might be suggested that there are better ways to preserve the objectivity of perceptual phenomenal character.

French and Phillips (2020) argue that it is possible to retain relationalism (and thereby also objectivism about phenomenal qualities such as colours) without the appeal to selectionism. Central to their proposal is the rejection of the following consequence of diaphaneity:

(Difference Principle) Necessarily, if two experiences differ in phenomenal character, then they differ in character-constituting presented elements.

Consider a red car under streetlights, looking orange to a human observer. According to selectionism, the car is both red and orange, and which of these colours is visible turns on whether it is seen in daylight or under streetlights. This analysis accords with the difference principle, in that it explains the phenomenal character solely in terms of the perceived items. French and Phillips consider attributing orangeness to the car unnecessary to explain why the car looks orange under streetlights. In their view, it suffices to say that the redness of the car looks orange when seen in this way (i.e. by this subject, in this illumination, etc.). By 'redness looks orange', they mean that (a) the psychological impact redness has on the subject when seen under streetlights is similar in the relevant way to (b) the psychological impact orangeness has on the subject when seen in daylight (French and Phillips 2020,12 ). On this view, '[t]he car's orange look is simply its red color' (French and Phillips 2020, 13).

This proposal was put forward as an alternative to selectionism and diaphaneity. In particular, French and Phillips claim that their view is incompatible with the Difference Principle on the grounds that it explains perceptual phenomenal character 
not only in terms of the perceived items, but also in terms of the ways in which those items are perceived. However, closer inspection reveals that this view it is either (i) implicitly committed to selectionism and diaphaneity, or (ii) explanatorily idle. Whether (i) or (ii) is the case turns on how the claim that a single item can be perceived in many different ways is interpreted.

We have already seen that French and Phillips specify the difference in ways of perceiving in terms of the difference in psychological impact the perceived item has on the subject. One could take this as suggesting that ways of perceiving do not concern the environment at all; they solely capture something about the subject (e.g. the reaction of the perceptual system to the stimulus on various occasions). But it would be a mistake to conceive of the ways of perceiving in this way.

Suppose that the car's redness is perceived on the two occasions, but in different ways. The activity in the perceptual system is also different on the two occasions. But the appeal to the difference in perceptual processing does not fully explain the phenomenal difference. A comprehensive explanation of the phenomenal difference has to mention the fact that the perceptual system is stimulated differently on the two occasions.

Consequently, there seems to be no way around the claim that it is the car's redness that looks different on the two occasions, i.e. that the car's redness has two different sensible aspects that are perceived on the two occasions. Because the complete explanation of the difference between various looks of the car's redness has to mention the difference in environmental stimulation of the perceptual system, the phenomenal difference in question is a difference in what is perceived on the two occasions, not just in how the brain reacts to what is perceived ${ }^{14}$.

But now the claim that what we are considering is an alternative to selectionism and diaphaneity is hard to believe, since the account in question entails that each colour has multiple looks, and which of those looks one sees turns on the way in which one sees that colour. How is this different from selectionism? After all, it would make perfect sense for the selectionist to say that which objective look of the object is selected by the perceptual system on a given occasion is a matter of the way in which the subject is related to that object. And this formulation of selectionism is clearly not incompatible with the Difference Principle ${ }^{15}$. If so, why think that French and Phillips' view is?

This objection cannot be rebutted by insisting that it is the same property (i.e. redness) that is seen in daylight and under streetlights. Denying that the subject is aware of different properties in these cases renders the explanation unintelligible. Even if we grant that red has an orange look, that look is distinct from red's red look.

\footnotetext{
$\overline{14}$ An anonymous referee asked: 'Why can't we say that there is one colour, and our brain interprets it differently under different environmental conditions?' I think one can say that, but this possibility is unacceptable for the relationalist because it suggests that the properties that constitute perceptual phenomenal character are produced in the brain, which is precisely what relationalism denies.

15 The account offered by French and Phillips would be incompatible with the Difference Principle if the way of perceiving was manifest in perceptual phenomenal character in the same way in which the perceived items are. But, as we have seen in the previous sections, there are strong reasons to the contrary.
} 
Otherwise the account fails to explain the phenomenological difference between the two cases (cf. Pautz forthcoming, 30-31).

In response, French and Phillips could suggest that their view only says that the car's redness looks red in daylight and orange under streetlights because it is seen in a different way in each case, period. In other words, they could dig in their heels and insist that the phenomenal difference is exhaustively explained by the claim that the car is perceived in a different way in each case. But this would effectively render their account explanatorily idle. If the proposal in question were limited to the claim that the car's redness looks red in daylight and orange under streetlights because it is seen in a different way in each case, it would be a virtus dormitiva explanation (it would merely restate the explanandum in different words). Everyone can agree that the car looks red in daylight and orange under streetlights because it is seen in a different way in each case. The question is what this difference amounts to, i.e. what constitutes the phenomenological difference between the two cases ${ }^{16}$. Why two experiences of the same car (in daylight vs. under streetlights) have different phenomenal characters? Put differently, why does the car look different on the two occasions? A possible explanans is the claim that the car is perceived in different ways on the two occasions. But what does it mean that the car is perceived in different ways? Given the foregoing, it seems that the only plausible relationalist answer to this question is selectionism.

A real alternative to selectionism is Beck's view (2019a; 2019b). While this account also revolves around the claim that an object can be perceived in different ways, it develops it in a way that is evidently inconsistent with diaphaneity and selectionism.

O. Beck proposes to analyse perception in terms of a three-place relation ' $x$ perceptually appears $\mathrm{W}$ to $\mathrm{S}$ '. The relata are the subject $\mathrm{S}$, the appearance property $\mathrm{W}$ instantiated by $S$, and the mind-independent item $x$. On this view, perceptual phenomenology is partially constituted by $\mathrm{W}$ (i.e. the way $\mathrm{S}$ is appeared to), which is entirely determined by S's neuro-computational properties, and partially by the perceived item x. W accommodates empirical evidence discussed above (e.g. attentional variation, good internal correlation) and the similarity between perception and hallucination, $\mathrm{x}$ accounts for the relationality of perception.

This account is intended as a middle way between intentionalism and relationalism about perception. The former construes perceptual phenomenal character as consistent with inexistence of the perceived object, whereas the latter views it as inconsistent with inexistence of the perceived object. Beck (2019b) thinks that this is because each of these two accounts presupposes a different conception of phenomenology. Intentionalism is based on a narrow conception, according to which perceptual phenomenal character is exhausted by the way the subject is appeared to. Relationalism is based on a broad conception, according to which perceptual phenomenal character is the way a certain object appears to the subject. O. Beck's

\footnotetext{
16 Incidentally, the account at issue structurally resembles a version of intentionalism that differentiates perception from sensory imagination in terms of modes of presentation, which is subject to the same objection (see Bourget 2017, 683).
} 
view is supposed to accommodate both conceptions: W accommodates the narrow conception, whereas the ' $\mathrm{x}$ appears $\mathrm{W}$ to $\mathrm{S}$ ' relation accommodates the broad conception.

Although this view avoids the controversies surrounding selectionism and diaphaneity, it faces other difficulties. The main problem is that the narrow vs. broad phenomenology distinction does not seem to accurately represent the dialectics in the intentionalism vs. relationalism debate. For it implies that both parties have been talking past each other for over two decades now, which is highly improbable. As I understand it, relationalism claims that the way the subject is appeared to when they perceive an object just is the way that object appears to the subject (cf. Brewer 2013, 422: 'What it is like for the subject is what it - the perceived object itself-is like, for the subject' $)^{17}$. The intentionalist disagrees because they believe that the subject can be appeared to in the same way no matter whether the subject is perceiving or merely hallucinating. The bone of contention is whether perceptual phenomenal character is essentially relational, i.e. whether perceptual phenomenal character is at least partially constituted by the perceived items. Hence relationalism is inconsistent with O. Beck's claim (Beck 2019a, 625) that the way the subject is appeared to is a property of the subject which is fully determined by the subject's neuro-computational properties.

Furthermore, the relationalist will reject the accusation of neglecting the narrow conception of phenomenology simply because they believe that the correct conception of perceptual phenomenology (i.e. phenomenology of genuine perception as opposed to hallucination) is the broad conception, and that no narrow conception of perceptual phenomenology can be correct.

Why is the relationalist going to balk at the narrow conception? By O. Beck's own admission (Beck 2019b, 4-5), the same appearance property (W) and its neural realizer can occur even if the perceived object is not around. As soon as we grant that what it is like for the subject to perceive an object is solely determined by that subject's appearance property and the neuro-computational state realizing that property, the role of the perceived object in explaining perceptual phenomenal character will be screened-off (i.e. rendered explanatorily irrelevant) by the explanatory role of that appearance property and its neural basis (Martin 2004; 2006).

According to Logue $(2013,127-28)$, just because a perceptual experience supervenes on a neural activity that can occur in the absence of the perceived object, it does not follow that the explanatory role of the perceived object is screened-off by that neural activity, since in cases of genuine perception that activity occurs in virtue of the fact that the object is perceived.

\footnotetext{
17 In other words, the way the object appears to the subject (or, in Beck's terminology, the way the subject is appeared to when they perceive the object) is the way the object really is. The properties that constitute the phenomenal character of genuine perception (as opposed to hallucination) are literally the properties that the perceived object has independently of being perceived. What it is like for the subject to see an object is literally what the object is like. The phrase 'for the subject' does not mean that the properties in question are represented to the subject, or somehow modified by the perceptual system. It only means that the way the object is like for the subject depends on which properties of the object are seen by the subject on that occasion.
} 
But this is beside the point. For the screening-off problem to arise, we do not have to assume that the subject is in exactly the same mental state when the experienced object is perceived and when it is merely hallucinated. The screening-off problem thrives on a more specific assumption that the subject is appeared to in the same way in both cases. If the way the genuinely perceiving subject is appeared to is consistent with the absence of the perceived object, and the only way to access the perceived object is via the way the subject is appeared to, then, for any perceptual episode, the claim that the way the subject is appeared to is an element in a relation involving the perceived object is in need of an a priori justification (cf. Travis 2017). Contrary to what Logue $(2013,130)$ suggests, relationalism was never intended to provide that justification. The relationalist claims that no such justification is necessary because the way one is appeared to when undergoing a genuine perception is such that "no experience like this, no experience of fundamentally the same kind, could have occurred had no appropriate candidate for awareness existed' (Martin 2004, 39) ${ }^{18}$.

While O. Beck's view fails to secure the objectivity of perceptual phenomenal character, the main virtue of selectionism and diaphaneity is precisely that they maintain the objectivity of perceptual phenomenal character. Insofar as my replies to objections against selectionism and diaphaneity are on the right track, none of those objections compels the relationalist to retreat to O. Beck's view, nor any other view of that sort (see e.g. Logue 2012).

\section{Conclusion}

Diaphaneity of perceptual experience is not undermined by phenomenological considerations about the boundaries of visual experience and blurry vision. Nor is diaphaneity incompatible with empirical evidence concerning attentional variation, the correlation between perceptual phenomenal character and various physical properties, and unconscious perception. Each of these phenomena admits of being explained in selectionist terms, and there are good reasons to prefer these explanations over those advocated by the critics. Of course, none of this shows that selectionism and diaphaneity are true. What it does show, however, is that both claims are much more resilient to criticism than they are usually taken to be, and that recent declarations of their falsity are premature.

Acknowledgments I am deeply grateful to an anonymous referee for this journal for their detailed and helpful comments.

Funding This work was supported by the National Science Center (Poland) under Grant Number 2019/32/C/HS1/00113.

\footnotetext{
18 In this connection, relationalism is viable insofar as it can be supplemented with a suitable account of illusion and hallucination (see e.g. Allen 2015; Ali 2018; Genone 2014; Phillips 2016b).
} 


\section{Declarations}

Conflict of interest The author declares that he has no conflict of interest.

Ethical Standards I comply with the Ethical Standards of "Axiomathes".

Open Access This article is licensed under a Creative Commons Attribution 4.0 International License, which permits use, sharing, adaptation, distribution and reproduction in any medium or format, as long as you give appropriate credit to the original author(s) and the source, provide a link to the Creative Commons licence, and indicate if changes were made. The images or other third party material in this article are included in the article's Creative Commons licence, unless indicated otherwise in a credit line to the material. If material is not included in the article's Creative Commons licence and your intended use is not permitted by statutory regulation or exceeds the permitted use, you will need to obtain permission directly from the copyright holder. To view a copy of this licence, visit http://creativecommons.org/licen ses/by/4.0/.

\section{References}

Ali R (2018) Does hallucinating involve perceiving? Philos Stud 175(3):601-627

Allen K (2015) Hallucination and imagination. Australas J Philos 93(2):287-302

Allen K (2016) A naïve realist theory of colour. Oxford University Press

Beck O (2019a) Rethinking naive realism. Philos Stud 176(3):607-633

Beck O (2019b) Two conceptions of phenomenology. Philosophers' Imprint 19(37):1-17

Beck J, Schneider KA (2017) Attention and mental primer. Mind Lang 32(4):463-494

Beck O (2020) Naive realism for unconscious perceptions. Erkenntnis

Berger J, Mylopoulos M (2019) On scepticism about unconscious perception. J Conscious Stud 26(11-12):8-32

Bermúdez JL (2000) Personal and sub-personal; a difference without a distinction. Philos Explor 3(1):63-82

Block N (1996) Mental paint and mental latex. Philosophical Issues 7:19-49

Block N (1999) Sexism, racism, ageism, and the nature of consciousness. Philos Top 26(1/2):39-70

Block N (2010) Attention and mental paint. Philosophical Issues 20:23-63

Block N (2011) The Anna Karenina theory of the unconscious. Neuropsychoanalysis 13(1):34-37

Block N (2012) The grain of vision and the grain of attention. Thought: A J Philos 1(3):170-84

Bohon K, Hermann K, Hansen T, Conway B (2016) Representation of perceptual color space in macaque posterior inferior temporal cortex (the V4 complex). Eneuro 3(4):0039-0116

Bourget D (2017) Why are some phenomenal experiences "vivid" and others "faint"? Representationalism, imagery, and cognitive phenomenology. Australas J Philos 95(4):673-687

Boyer JL, Harrison S, Ro T (2005) Unconscious processing of orientation and color without primary visual cortex. Proc Natl Acad Sci USA 102(46):16875-16879

Breitmeyer BG (2015) Psychophysical “"blinding"” methods reveal a functional hierarchy of unconscious visual processing. Conscious Cogn 35:234-250

Brewer B (2011) Perception and its objects. Oxford University Press, Oxford

Brewer B (2013) Attention and direct realism. Anal Philos 54(4):421-435

Brouwer G, Heeger D (2013) Categorical clustering of the neural representation of color. J Neurosci 33:15454-15465

Burnyeat M (1979) Conflicting appearances. Proceedings of the British Academy 65:69-111

Campbell J (2002) Reference and consciousness. Oxford University Press

Campbell J (2009) Consciousness and reference. In: Beckermann A, McLaughlin B, Walter S (eds)

The Oxford handbook of philosophy of mind. Oxford University Press, Oxford, pp 648-62

Campbell J, Cassam Q (2014) Berkeley's puzzle: What does experience teach us? Oxford University Press, Oxford

Carrasco M, Ling S, Read S (2004) Attention alters appearance. Nat Neurosci 7(3):308-313 
Chang EF, Rieger JW, Johnson K, Berger MS, Barbaro NM, Knight RT (2010) Categorical speech representation in human superior temporal gyrus. Nat Neurosci 13:1428-1432

Coates P, Coleman S (2015) Introduction. In: Coates P, Coleman S (eds) Phenomenal qualities: sens. Oxford University Press, Oxford

Coleman, S. 2020. 'Painfulness, Suffering, and Consciousness'. In Philosophy of Suffering. Metaphysics, Value, and Normativity, edited by D. Bain, M. Brady, and J. Corns, 55-74. Routledge.

Drayson Z (2012) The uses and abuses of the personal/subpersonal distinction. Philos Perspect 26(1):1-18

Fish W (2009) Perception, hallucination, and illusion. Oxford University Press, Oxford

French C (2014) Naive realist perspectives on seeing blurrily. Ratio 27(4):393-413

French C (2016) Idiosyncratic perception. Philos Q 66(263):391-399

French C (2018) Naïve realism and diaphaneity. Proc Aristot Soc 118(2):149-175

French C, Phillips I (2020) Austerity and illusion. Philosophers' Imprint 20(15):1-19

French C, Phillips I forthcoming Naïve realism, the slightest philosophy, and the slightest science. In McLaughlin B, Cohen J Contemporary debates in the philosophy of mind

Genone J (2014) Appearance and illusion. Mind 123(490):339-376

Goldstein B (2009) Sensation and perception. Wadsworth, Pacific Grove

Gow L (2016) The limitations of perceptual transparency. Philos Q 66(265):723-744

Gow L (2019) Everything is clear: all perceptual experiences are transparent. Eur J Philos 27:412-425

Howard JD, Plailly J, Grueschow M, Haynes JD, Gottfried JA (2009) Odor quality coding and categorization in human posterior piriform cortex. Nat Neurosci 12:932-939

Kalderon ME (2007) Color pluralism. Philos Rev 116(4):563-601

Kalderon ME (2008) Metamerism, constancy, and knowing which. Mind 117(468):935-971

Kalderon ME (2011a) Color Illusion. Noûs 45(4):751-775

Kalderon ME (2011b) The multiply qualitative. Mind 120(478):239-262

Kalderon ME (2018) Experiential pluralism and the power of perception. In: Collins J, Dobler T (eds) The philosophy of Charles Travis: language, thought, and perception. Oxford University Press, Oxford, pp 222-36

Kind A (2003) What's so transparent about transparency? Philos Stud 115:225-244

Logue H (2012) Why naive realism? Proc Aristot Soc 112:211-237

Logue H (2013) Good news for the disjunctivist about (one of) the bad cases. Philos Phenomenol Res 86(1):105-133

MacAdam DL (1985) The physical basis of color specification. In: Color measurement: theme and variations, Springer, New York, pp 1-25

Margot C (2009) A noseful of objects. Nat Neurosci 12:813-814

Martin MGF (1992) Sight and touch. In: Crane T (ed) The contents of experience. Cambridge University Press, Cambridge

Martin MGF (1998) Setting things before the mind. In: O'Hear A (ed) Current issues in philosophy of mind. Cambridge University Press, Cambridge

Martin MGF (2004) The limits of self-awareness. Philos Stud 120(1/3):37-89

Martin MGF (2006) On being alienated. In: Gendler T, Hawthorne J (eds) Perceptual experience. Oxford University Press, Oxford, pp 354-410

Martin MGF (2015) Moore's dilemma. In: Coates P, Coleman S (eds) Phenomenal qualities: sense, perception, and consciousness. Oxford University Press, Oxford

Marvan T, Polák M (2017) unitary and dual models of phenomenal consciousness. Conscious Cogn $56: 1-12$

Mizrahi V (2006) Color objectivism and color pluralism. Dialectica 60(3):283-306

Moore GE (1922) The refutation of idealism. In: Philosophical studies, pp 1-30. Routledge, London.

Moutoussis K, Zeki S (2002) The relationship between cortical activation and perception investigated with invisible stimuli. Proc Natl Acad Sci USA 99(14):9527-9532

Norman LJ, Akins K, Heywood A, Kentridge RW (2014) Color constancy for an unseen surface. Curr Biol 24(23):2822-2826

Pautz A (2017) Experiences are representations: an empirical argument. In: Nanay B (ed) Current controversies in philosophy of perception. Routledge, New York, pp 23-42

Pautz A forthcoming Naïve realism and the science of sensory consciousness. Anal Philos

Phillips I (2016a) Consciousness and criterion: on block's case for unconscious seeing. Philos Phenomenol Res 93(2):419-451

Phillips I (2016b) Naïve realism and the science of (some) illusions. Philos Top 44(2):353-380 
Phillips I (2018) Unconscious perception reconsidered. Anal Philos 59(4):471-514

Polák M, Marvan T (2019) How to mitigate the hard problem by adopting the dual theory of phenomenal consciousness. Front Psychol. https://doi.org/10.3389/fpsyg.2019.02837

Prinz J (2010) When is perception conscious? In: Nanay B (ed) Perceiving the world. Oxford University Press, Oxford, pp 310-32

Railo H, Salminen-Vaparanta N, Henriksson L, Revonsuo A, Koivisto M (2012) Unconscious and conscious processing of color rely on activity in early visual cortex: a TMS study. J Cogn Neurosci 24(4):819-829

Richardson L (2010) Seeing empty space. Eur J Philos 18(2):227-243

Ro T, Singhal NS, Breitmeyer BG, Garcia JO (2009) Unconscious processing of color and form in metacontrast masking. Atten Percept Psychophys 71(1):95-103

Rosenthal DM (2010) How to think about mental qualities. Philosophical Issues 20(1):368-393

Schneider KA, Komlos M (2008) Attention biases decisions but does not alter appearance. J vis $8(15): 1-10$

Siegel S (2010) The contents of visual experience. Oxford University Press, New York

Skrzypulec B (2021) Blur and interoceptive vision. Philos Stud 178:3271-3289

Skrzypulec B (2021b) Contents of unconscious color perception. Rev Philos Psychol

Smith AD (2008) Translucent experiences. Philos Stud 140(2):197-212

Soteriou M (2013) The mind's construction: the ontology of mind and mental action. Oxford University Press, Oxford

Stoljar D (2004) The argument from diaphanousness. Can J Philos 34(sup1):341-390

Stoneham T (2008) A neglected account of perception. Dialectica 62(3):307-322

Travis C (2004) Silence of the senses. Mind 113:57-94

Travis C (2017) Deliverances (indirection). Topoi 36(2):229-246

Travis C (2018) Reply to Keith A. Wilson. In: Collins J, Dobler T (eds) The philosophy of charles travis: language, thought, and perception. Oxford University Press, Oxford

Van Cleve J (2015) Troubles for radical transparency. In: Horgan T, Sabatés M, Sosa E (eds) Qualia and mental causation in the physical world: themes from the philosophy of Jaegwon Kim. Cambridge University Press, Cambridge

Weiskrantz L (1986) Blindsight. Oxford University Press, A Case Study and Implications

Weksler A, Jacobson H, Bronfman ZZ (2021) The Transparency of experience and the neuroscience of attention. Synthese 198(5):4709-4730

Wong HY (2014) Personal and sub-personal: overcoming explanatory apartheid. In: Hung TW, Communicative action. selected papers of the 2013 IEAS conference on language and action. Springer

Zięba PJ (2019) Naïve realism about unconscious perception. Synthese 196(5):2045-2073. https://doi. org/10.1007/s11229-017-1570-1

Publisher's Note Springer Nature remains neutral with regard to jurisdictional claims in published maps and institutional affiliations. 